\title{
MICROBIOTA ASSOCIATED WITH CHRONIC OSTEOMYELITIS OF THE JAWS
}

\section{Elerson Gaetti-Jardim Júnior ${ }^{1,3}$, Angélica Cristiane Fardin ${ }^{1}$, Ellen Cristina Gaetti-Jardim ${ }^{1}$, Alvimar Lima de Castro ${ }^{1}$, Christiane Marie Schweitzer², Mario Julio Avila-Campos ${ }^{3}$}

\author{
${ }^{1}$ Faculdade de Odontologia de Araçatuba, Departamento de Patologia, Universidade Estadual Paulista, Araçatuba, SP, Brasil; \\ ${ }^{2}$ Centro de Matemática, Computação e Cognição, Universidade Federal do ABC, Santo André, SP, Brasil; ${ }^{3}$ Laboratório de \\ Anaeróbios, Departamento de Microbiologia, Universidade de São Paulo, São Paulo, Brasil.
}

Submitted: August 25, 2009; Returned to authors for corrections: December 11, 2009; Approved: May 25, 2010.

\begin{abstract}
Chronic osteomyelitis of maxilla and mandible is rare in industrialized countries and its occurrence in developing countries is associated with trauma and surgery, and its microbial etiology has not been studied thoroughly. The aim of this investigation was to evaluate the microbiota associated with osteomyelitis of mandible or maxilla from some Brazilian patients. After clinical and radiographic evaluation, samples of bone sequestra, purulent secretion, and biopsies of granulomatous tissues from twenty-two patients with chronic osteomyelitis of mandible and maxilla were cultivated and submitted for pathogen detection by using a PCR method. Each patient harbored a single lesion. Bacterial isolation was performed on fastidious anaerobe agar supplemented with hemin, menadione and horse blood for anaerobes; and on tryptic soy agar supplemented with yeast extract and horse blood for facultative bacteria and aerobes. Plates were incubated in anaerobiosis and aerobiosis, at $37^{\circ} \mathrm{C}$ for 14 and 3 days, respectively. Bacteria were cultivated from twelve patient samples; and genera Actinomyces, Fusobacterium, Parvimonas, and Staphylococcus were the most frequent. By PCR, bacterial DNA was detected from sixteen patient samples. The results suggest that cases of chronic osteomyelitis of the jaws are usually mixed anaerobic infections, reinforcing the concept that osteomyelitis of the jaws are mainly related to microorganisms from the oral environment, and periapical and periodontal infections may act as predisposing factors.
\end{abstract}

Key words: osteomyelitis, bacteria, anaerobes, maxilla, mandible.

\section{INTRODUCTION}

Chronic osteomyelitis is a relapsing and persistent infection that evolves over months to years and is characterized by low-grade inflammation, presence of bone sequestra, new bone apposition, and, some times, fistulous tracts. (28) In contrast to acute purulent osteomyelitis, chronic osteomyelitis is characterized by a low-grade clinical presentation, with lymphocyte and plasma cell infiltrates with necrotic areas and some bone condensation (28).

Its occurrence in the craniofacial skeleton is rarely observed in industrialized countries (1). However, this infection is prevalent in developing countries, where it is frequently associated with trauma and surgery, and its incidence, clinical signs and microbial etiology have not been studied thoroughly (22). In the maxillofacial skeleton, 
chronic osteomyelitis is more often observed in the mandible and maxilla; and it can be limited to a unique anatomic site or spread to other areas, particularly in individuals presenting impairment of the immune response, non-controlled diabetes and hospitalized patients (3).

The pathogenesis of osteomyelitis may be induced either by hematogenous origin or by dissemination of local infections, and its treatment involves removal of bone sequestra, lesion debridement, and bone decortication associated with systemic antibiotic therapy $(7,10)$. However, in some patients, these infections are refractory to surgery and antibiotic therapy (7), requiring an adequate microbiological diagnosis $(10,16)$.

The occurrence, type, severity and clinical prognosis of osteomyelitis depend upon several factors, including the characteristics and virulence of the infecting pathogen, host immune response and source of infection (3). In addition, rapid and accurate microbiological osteomyelitis diagnosis is crucial to delineate the appropriate antibiotic therapy.

Thus, the aim of the present study was to evaluate the microbiota associated with chronic osteomyelitis of maxilla and mandible.

\section{MATERIAL AND METHODS}

\section{Patients and Sample Collection}

A total of twenty-two patients (14 males and 8 females); aged from 13 to 67 years old (mean, 51.43 years) with clinical and radiographic signs of chronic osteomyelitis seen at the School of Dentistry of Araçatuba, São Paulo State University (UNESP) and at School of Dentistry of Santa Fé do Sul (FUNEC), Brazil were selected. Samples were collected between February 2000 and November 2008. All patients gave written informed consent to be included in this study, which was approved by the Institutional Review Boards of the Universities mentioned above (UNESP, 0063/2000 and 136/2007; FUNEC, 03/2008).

All patients underwent clinical interview to obtain information about their identification, age, ethnic aspects, family and past medical history, followed by clinical and radiographic evaluation of the bone lesion, periodontium and teeth. The most frequent clinical findings are presented in Table 2. Patients exhibiting uncontrolled significant cardiovascular, pulmonary, diabetes mellitus, renal or hepatic disease; submitted to radiotherapy or therapy with bisphosphonates, steroid drugs treatment, or self-medication with antibiotics three months prior to the beginning of the treatment were excluded from this study (28). Six months prior to treatment, six patients had made use of self-medication with amoxicillin and two patients had taken ciprofloxacin and cephalexin orally for 7-14 days.

Only bone biopsy, bone sequestra, bone marrow, granulation tissue and aspirated pus specimens were acceptable for microbial diagnosis. In order to avoid cross-contamination from oral microorganisms, the clinical specimens were obtained intra-orally through surgical procedures, avoiding contact with soft tissues, oral environment and sinus tracts. When possible, samples of bone or granulation tissues were also obtained for histopathological analysis (22). When bone biopsies were removed, areas of the margin of the osteolytic lesion were preferred and removed with chisels and osteotome.

Lesion samples were immediately placed into a tube containing VMGA III medium (21) and $250 \mu$ l of ultra-pure water (Milli-Q Water Purification System, Millipore, Milford, MA, USA), and stored at $-196^{\circ} \mathrm{C}$, until DNA extraction.

\section{Isolation and Identification of Microorganisms}

The collected samples were processed within $2 \mathrm{~h}$. Samples in VMGA III were submitted to serial 10-fold dilutions and plated onto fastidious anaerobe agar (FAA) enriched with 5 $\mu \mathrm{g} / \mathrm{mL}$ hemin, $1 \mu \mathrm{g} / \mathrm{mL}$ menadione, $0.5 \%$ yeast extract and $5 \%$ horse blood. Plates were incubated in anaerobiosis $\left(90 \% \mathrm{~N}_{2}+\right.$ $10 \% \mathrm{CO}_{2}$ ) at $37^{\circ} \mathrm{C}$, for 10 days, for isolation of anaerobes. Additionally, samples were also incubated onto tryptic soy agar (TSA) supplemented with $5 \%$ horse blood, $0.5 \%$ yeast extract and incubated at $37^{\circ} \mathrm{C}$ for $48 \mathrm{~h}$, for aerobic and facultative bacteria.

Isolates were identified by Gram staining, colony 
morphology on blood agar plates, and by the use of biochemical identification kits Rapid ID 32 A (BioMérieux SA, Marcy-1'Etoile, France) for strict anaerobic Gram-negative and -positive rods; RapIDANA II System (Innovative Diagnostic Systems Inc., Atlanta, GA, USA) for strict anaerobic Gram-positive cocci; API Staph (BioMérieux) for staphylococci (Gram-positive cocci, catalase-positive); Rapid
ID 32Strep (BioMérieux) for streptococci (Gram-positive cocci, catalase-negative); Rapid NH System (Innovative Diagnostic Systems Inc, Atlanta, GA, USA) for genus Eikenella and API 20E (BioMérieux) for facultative enteric rods. In addition, $P$. intermedia and $P$. nigrescens isolates were confirmed by DNA amplification through PCR (13).

Table 2. Clinical history data of 22 patients with chronic osteomyelitis.

\begin{tabular}{|c|c|}
\hline Characteristic & $\mathbf{N}(\%)$ \\
\hline \multicolumn{2}{|l|}{ History of tobacco consumption } \\
\hline Yes & $13(59.1)$ \\
\hline No & $9(40.9)$ \\
\hline \multicolumn{2}{|l|}{ History of Dental extractions } \\
\hline Yes & $4(18.2)$ \\
\hline No & $18(81.8)$ \\
\hline \multicolumn{2}{|l|}{ Periodontal conditions } \\
\hline Gingivitis & $8(36.4)$ \\
\hline Lateral periodontitis & $13(59.1)$ \\
\hline Apical periodontitis & $3(13.6)$ \\
\hline \multicolumn{2}{|l|}{ Evolution period } \\
\hline Within 8 to 12 weeks & $7(31.8)$ \\
\hline From 13 to 30 weeks & $11(50.0)$ \\
\hline Over 31 weeks & $4(18.8)$ \\
\hline \multicolumn{2}{|l|}{ Anatomical region affected by osteomyelitis } \\
\hline Left mandibular body & $6(27.3)$ \\
\hline Right mandibular body & $8(36.4)$ \\
\hline Mental & $3(13.6)$ \\
\hline Maxillary posterior & $5(22.7)$ \\
\hline \multicolumn{2}{|l|}{ Main symptomatology of osteomyelitis } \\
\hline Bone sequestra & $10(45.5)$ \\
\hline Intraoral pus discharge (intraoral fistula) & $5(22.7)$ \\
\hline Extraoral pus discharge (extraoral fistula) & $1(4.5)$ \\
\hline Long-standing localized bone pain & $8(36.4)$ \\
\hline Erythema & $1(4.5)$ \\
\hline Periosteal thickening and bony irregularities & $7(31.8)$ \\
\hline Radiographic alterations suggesting osteolytic lesions and areas of bone condensation & $16(72.7)$ \\
\hline
\end{tabular}

\section{Detection of Pathogens by PCR}

The presence of microorganisms that have frequently been isolated from oral and bone infections was also evaluated by PCR. Presence of Actinomyces israelii, A. naeslundii, A. viscosus (27), Aggregatibacter actinomycetemcomitans, Campylobacter rectus, Dialister pneumosintes, Eikenella corrodens, Fusobacterium nucleatum, Porphyromonas gingivalis, Prevotella intermedia, Tannerella forsythia, Treponema denticola (2), family Enterobacteriaceae (11), genus Enterococcus (13), E. faecalis (12), E. faecium (9), Parvimonas micra, Porphyromonas endodontalis, Prevotella nigrescens (13), Propionibacterium acnes (14), genus Pseudomonas, P. aeruginosa (25), genus Staphylococcus (20), Streptococcus mutans, S. oralis, S. salivarius, S. sanguinis, and S. sobrinus (15) was determined by PCR using specific primer pairs (Table 1). Additionally, a universal primer pair specific for bacterial 16S rDNA was used to detect DNA from all eubacterial species present in the samples (13). 
Table 1. Nomenclature, oligonucleotide sequence and annealing temperature of the species-specific primer pairs for PCR.

\begin{tabular}{|c|c|c|c|}
\hline Microorganism & Primer sequences $\quad\left(5^{\prime} \rightarrow 3^{\prime}\right)$ & Annealing temperature & Amplicon (bp) \\
\hline A. israelii* & $\begin{array}{l}\text { GGT CTG CCT TGT TTT TTG CGG GGT GGG } \\
\text { CAT AAC CCG GCT ACC GTC AAC C }\end{array}$ & $60^{\circ} \mathrm{C}$ & 439 \\
\hline A. naeslundii* & $\begin{array}{c}\text { GCG CCT TTT TTG GTG TTT TTG G } \\
\text { CAC CCA CAA ACG AGG CAG GCC TG }\end{array}$ & $60^{\circ} \mathrm{C}$ & 274 \\
\hline A. viscosus* & $\begin{array}{c}\text { GTG AAG GAG CCA GCT TGC TGG TTC TG } \\
\text { CGG AAC AAA CCT TTC CCA GGC }\end{array}$ & $60^{\circ} \mathrm{C}$ & 155 \\
\hline $\begin{array}{c}A . \\
\text { actinomycetemcomitans } * *\end{array}$ & $\begin{array}{l}\text { GCT AAT ACC GCG TAG AGT CGG } \\
\text { ATT TCA CAC CTC ACT TAA AGG T }\end{array}$ & $50^{\circ} \mathrm{C}$ & 500 \\
\hline C. rectus $* *$ & $\begin{array}{l}\text { TTT CGG AGC GTA AAC TCC TTT TC } \\
\text { TTT CTG CAA GCA GAC ACT CTT }\end{array}$ & $50^{\circ} \mathrm{C}$ & 600 \\
\hline D. pneumosintes* & $\begin{array}{l}\text { TTC TAA GCA TCG CAT GGT GC } \\
\text { GAT TTC GCT TCT CTT TGT TG }\end{array}$ & $55^{\circ} \mathrm{C}$ & 1105 \\
\hline E. corrodens $* *$ & $\begin{array}{l}\text { CTA ATA CCG CAT ACG TCC TAA G } \\
\text { CTA CTA AGC AAT CAA GTT GCC C }\end{array}$ & $45^{\circ} \mathrm{C}$ & 688 \\
\hline Enterobacteriaceae $^{* *}$ & $\begin{array}{l}\text { AAC CAG TTC CGC GTT GGC CTG G } \\
\text { CCT GAA CAA CAC GCT CGG A }\end{array}$ & $50^{\circ} \mathrm{C}$ & 1150 \\
\hline genus Enterococcus* & $\begin{array}{l}\text { TAC TGA CAA ACC ATT CAT GAT G } \\
\text { AAC TTC GTC ACC AAC GCG AAC }\end{array}$ & $55^{\circ} \mathrm{C}$ & 112 \\
\hline E. faecalis* & $\begin{array}{l}\text { ATC AAG TAC AGT TAG TCT } \\
\text { ACG ATT CAA AGC TAA CTG }\end{array}$ & $45^{\circ} \mathrm{C}$ & 941 \\
\hline E. faecium* & $\begin{array}{l}\text { TTG AGG CAG ACC AGA TTG ACG } \\
\text { TAT GAC AGC GAC TCC GAT TCC }\end{array}$ & $65^{\circ} \mathrm{C}$ & 658 \\
\hline F. nucleatum $* *$ & $\begin{array}{l}\text { ATT GTG GCT AAA AAT TAT AGT T } \\
\text { ACC CTC ACT TTG AGG ATT ATA G }\end{array}$ & $40^{\circ} \mathrm{C}$ & 1010 \\
\hline P. micra** & $\begin{array}{c}\text { AGA GTT TGA TCC TGG CTC AG } \\
\text { ATA TCA TGC GAT TCT GTG GTC TC }\end{array}$ & $60^{\circ} \mathrm{C}$ & 207 \\
\hline P. endodontalis & $\begin{array}{l}\text { GCT GCA GCT CAA CTG TAG TC } \\
\text { CCG CTT CAT GTC ACC ATG TC }\end{array}$ & $60^{\circ} \mathrm{C}$ & 672 \\
\hline P. gingivalis** & $\begin{array}{l}\text { AGG CAG CTT GCC ATA CTG CG } \\
\text { ACT GTT AGC AAC TAC CGA TGT }\end{array}$ & $60^{\circ} \mathrm{C}$ & 404 \\
\hline P. intermedia** & $\begin{array}{l}\text { TTT GTT GGG GAG TAA AGC GGG } \\
\text { TCA ACA TCT CTG TAT CCT GCG T }\end{array}$ & $50^{\circ} \mathrm{C}$ & 575 \\
\hline P. nigrescens $* *$ & $\begin{array}{l}\text { ATG AAA CAA AGG TTT TCC GGT AAG } \\
\text { CCC ACG TCT CTG TGG GCT GCG A }\end{array}$ & $55^{\circ} \mathrm{C}$ & 804 \\
\hline Microorganism & Primer sequences $\quad\left(5^{\prime} \rightarrow 3^{\prime}\right)$ & Annealing temperature & Amplicon length (bp) \\
\hline P. acnes** & $\begin{array}{c}\text { GGG TTG TAA (A/T)CC GCT TTC GCC TG } \\
\text { GGG ACA CCC ATC TCT GAG CAC }\end{array}$ & $50^{\circ} \mathrm{C}$ & 587 \\
\hline genus Pseudomonas * & $\begin{array}{l}\text { GAC GGG TGA GTA ATG CCT A } \\
\text { CAC TGG TGT TCC TTC CTA TA }\end{array}$ & $54^{\circ} \mathrm{C}$ & 618 \\
\hline P. aeruginosa* & $\begin{array}{l}\text { GGG GGA TCT TCG GAC CTC A } \\
\text { TCC TTA GAG TGC CCA CCC G }\end{array}$ & $58^{\circ} \mathrm{C}$ & 956 \\
\hline genus Staphylococcus * & $\begin{array}{l}\text { GGC CGT GTT GAA CGT GGT CAA ATC A } \\
\text { TIA CCA TTT CAG TAC CTT CTG GTA A }\end{array}$ & $55^{\circ} \mathrm{C}$ & 370 \\
\hline S. mutans** & $\begin{array}{l}\text { GGC ACC ACA ACA TTG GGA AGC TCA GTT } \\
\text { GGA ATG GCC GCT AAG TCA ACA GGA T }\end{array}$ & $60^{\circ} \mathrm{C}$ & 433 \\
\hline S. oralis** & $\begin{array}{c}\text { TCC CGG TCA GCA AAC TCC AGC C } \\
\text { GCA ACC TTT GGA TTT GCA AC }\end{array}$ & $60^{\circ} \mathrm{C}$ & 374 \\
\hline S. salivarius** & $\begin{array}{l}\text { GTG TTG CCA CAT CTT CAC TCG CTT CGG } \\
\text { CGT TGA TGT GCT TGA AAG GGC ACC ATT }\end{array}$ & $60^{\circ} \mathrm{C}$ & 544 \\
\hline S. sanguinis $* *$ & $\begin{array}{l}\text { GATAGTGGCTCAGGGCAGCCAGTT } \\
\text { GAACAGTTGCTGGACTTGCTTGTC }\end{array}$ & $60^{\circ} \mathrm{C}$ & 313 \\
\hline S. sobrinus** & $\begin{array}{l}\text { GAT GAT TTG GCT CAG GAT CAA TCC TC } \\
\text { ACT GAG CCA GTA GTA GAC TTG GCA ACT }\end{array}$ & $60^{\circ} \mathrm{C}$ & 325 \\
\hline T. forsythia** & $\begin{array}{l}\text { GCG TAT GTA ACC TGC CCG CA } \\
\text { TGC TTC AGT GTC AGT TAT ACC T }\end{array}$ & $60^{\circ} \mathrm{C}$ & 641 \\
\hline T. denticola** & $\begin{array}{l}\text { TAA TAC CGA ATG TGC TCA TTT ACA T } \\
\text { TCA AAG AAG CAT TCC CTC TTC TTC TTA }\end{array}$ & $60^{\circ} \mathrm{C}$ & 316 \\
\hline Universal $^{* *}$ & $\begin{array}{l}\text { AGA GTT TGA TCC TGG CTC AG } \\
\text { ACG GCT ACC TTG TTA CGA CTT }\end{array}$ & $56^{\circ} \mathrm{C}$ & 1500 \\
\hline
\end{tabular}

* Thermal cycler programmed for $94^{\circ} \mathrm{C}(5 \mathrm{~min})$, followed by 35 cycles at $94^{\circ} \mathrm{C}$ for $1 \mathrm{~min}$, annealing temperature adequate for each primer pair for 1 min, then $72^{\circ} \mathrm{C}$ for 90 seconds, and final extension at $72^{\circ} \mathrm{C}(10 \mathrm{~min})$;

**Thermal cycler programmed for $94^{\circ} \mathrm{C}(5 \mathrm{~min})$, followed by 30 cycles at $94^{\circ} \mathrm{C}$ for 30 seconds; annealing temperature adequate for each primer pair for 30 seconds, then $72^{\circ} \mathrm{C}$ for 30 seconds, and final extension at $72^{\circ} \mathrm{C}(5 \mathrm{~min})$. 
Bacterial DNA from each sample placed in sterile ultrapure water was obtained by using a QIAamp DNA Mini Kit (Qiagen, Hilden, Germany). Purified genomic DNA from reference strains of tested microorganisms were used as positive controls. DNA concentrations were determined spectrophotometrically $\left(\mathrm{A}_{260 \mathrm{~nm}} ;\right.$ Model DU-640, Beckman Instruments, Richmond, Wash, USA).

PCR amplification was performed in volumes of $25 \mu \mathrm{L}$ containing $1 \mathrm{X} \mathrm{PCR} / \mathrm{Mg}^{++}$buffer (Boehring Mannheim, Indianapolis, IN, USA), $0.2 \mathrm{mM}$ of each dNTP (Pharmacia Biotech, Piscataway, NJ, USA), 0.5 U Taq DNA polymerase (Invitrogen do Brasil, São Paulo, SP, Brazil), $0.4 \mu \mathrm{M}$ of each primer pair (Invitrogen) and $10 \mathrm{ng}$ of DNA template, using a DNA Thermal Cycler (Perkin Elmer, GeneAmp PCR System 9700, Norwalk, CT, USA). The conditions and oligonucleotides used in DNA amplification are presented in Table 1.

Amplification products were submitted to electrophoresis in $1 \%$ agarose gel in $1 \mathrm{X}$ TBE buffer $(1 \mathrm{M}$ Tris, $0.9 \mathrm{M}$ boric acid, 0.01 M EDTA, pH 8.4, Invitrogen, SP, Brazil), stained with $0.5 \mathrm{mg} / \mathrm{mL}$ of ethidium bromide and photographed on a UV light transilluminator (Eastman Kodak Co., NY, USA).

\section{Statistical analysis}

Differences between clinical parameters and the frequency of pathogen detection for each subject were analyzed by using the Chi-square or Fisher's exact test. Inter-relationships among different microorganisms were evaluated using the Spearman correlation coefficient test.

\section{RESULTS}

The data presented in Table 1 evidenced that most patients with chronic osteomyelitis were smokers (59.1\%), presented gingivitis $(36.4 \%)$ or periodontitis $(59.1 \%)$, and this infection was more frequent in mandible. In contrast, maxilla was affected just in a five cases $(22.7 \%)$ and the posterior range was the unique anatomical site affected in this bone. In seven patients $(31.8 \%)$, osteomyelitis showed a possible relationship with previous dental extractions or endodontic treatment.
The microbiota associated with maxillary osteomyelitis was similar to that observed in the mandibular cases. By using culture, single or multiple microorganisms were detected from 12 samples (Table 3), while single or multiple microorganisms were detected from 16 samples through PCR (Table 4). All positive samples by culture were also positive by PCR; moreover, two samples of bone biopsy and two specimens of bone sequestra produced positive results only by PCR. Microbial contamination was not detected either by PCR or culture in five osteomyelitis samples; four of the mandible and one of the maxilla.

Cultivated samples evidenced monomicrobial infection by S. aureus in two patients and by Staphylococcus sp. in one patient. Monomicrobial infections caused by strict anaerobes were not observed, but their association with facultative anaerobic cocci and rods was reported in nine cases.

By PCR, mixed infections were detected in fourteen samples, and strict anaerobes were presented in all these positive samples. Monomicrobial infections caused by Staphylococcus sp. were detected in only two samples (Table 4). An average of 3.8 species of strict anaerobes and 1.5 species of aerobes and facultative anaerobes were detected or cultivated per specimen, and this phenomenon was statistically significant (Chi-square test, $p=0.031$ ).

In this study, the most frequently cultivated microorganisms were Parvimonas micra, Staphylococcus aureus, Fusobacterium nucleatum and actinomycetes. Other bacteria, such as Propionibacterium acnes, Porphyromonas gingivalis, Prevotella intermedia, P. nigrescens, Streptococcus oralis, Eikenella corrodens, Enterococcus faecalis, Campylobacter rectus and facultative gram-negative enteric rods were also observed (Table 3). By PCR (Table 4), the detection frequencies of targeted microorganisms were usually higher than those observed by culture.

In the five patients with chronic suppuration and intraoral fistula, high numbers of Fusobacterium nucleatum were observed. Results from PCR suggest a synergistic association between $E$. corrodens and $F$. nucleatum (Chi-square test, $p=$ 0.043). Actinomycetes were detected in all lesions with bone 
sequestra by culture and PCR methods (Fisher's exact test, $p=$ 0.027).

Moreover, A. actinomycetemcomitans, D. pneumosintes,
E. faecium, $P$. endodontalis, S. mutans, $S$. salivarius, $S$. sanguinis, S. sobrinus, T. forsythia and pseudomonads were not detected by either culture or PCR methods.

Table 3. Microorganisms cultivated from twenty-two cases of chronic osteomyelitis of the jaws.

\begin{tabular}{cc}
\hline Microorganism & Prevalence $\mathbf{N}(\%)$ \\
\hline Actinomyces israelii & $3(13.6)$ \\
Actinomyces naeslundii & $3(13.6)$ \\
Actinomyces viscosus & $1(4.5)$ \\
Campylobacter rectus & $3(13.6)$ \\
Eikenella corrodens & $1(4.5)$ \\
Enterococcus faecalis & $1(4.5)$ \\
Enterobacter cloacae & $1(4.5)$ \\
Fusobacterium nucleatum & $5(22.7)$ \\
Porphyromonas gingivalis & $4(18.2)$ \\
Prevotella intermedia & $2(9.1)$ \\
Prevotella nigrescens & $2(9.1)$ \\
Propionibacterium acnes & $1(4.5)$ \\
Parvimonas micra & $6(27.3)$ \\
Proteus vulgaris & $2(9.1)$ \\
Providencia sp. & $1(4.5)$ \\
Staphylococcus sp. & $3(13.6)$ \\
Staphylococcus aureus & $5(22.7)$ \\
Streptococcus oralis & $2(9.1)$ \\
Single microorganism & $3(13.6)$ \\
Multiple microorganisms & $9(40.9)$ \\
\hline microorganism + Multiple microorganisms & $12(54.5)$ \\
\hline
\end{tabular}

Table 4. Microorganisms detected by PCR from twenty-two cases of chronic osteomyelitis of the jaws.

\begin{tabular}{cc}
\hline Microorganisms & Prevalence N(\%) \\
\hline Actinomyces israelii & $5(22.7)$ \\
Actinomyces naeslundii & $3(13.6)$ \\
Actinomyces viscosus & $3(13.6)$ \\
Campylobacter rectus & $4(18.2)$ \\
Eikenella corrodens & $4(18.2)$ \\
Enterobacteriaceae & $6(27.3)$ \\
Enterococcus faecalis. & $3(13.6)$ \\
Fusobacterium nucleatum & $7(31.8)$ \\
Porphyromonas gingivalis & $4(18.2)$ \\
Prevotella intermedia & $4(18.2)$ \\
Prevotella nigrescens & $3(13.6)$ \\
Propionibacterium acnes & $3(13.6)$ \\
Parvimonas micra & $8(36.4)$ \\
Staphylococcus spp. & $8(36.4)$ \\
Streptococcus oralis & $3(13.6)$ \\
Treponema denticola & $1(4.5)$ \\
No microorganism & $6(27.3)$ \\
Single microorganism & $2(9.1)$ \\
Multiple microorganisms & $14(63.6)$ \\
\hline
\end{tabular}




\section{DISCUSSION}

Odontogenic infection is the most common cause of osteomyelitis of the jaws, although other causes including injury, malignant tumors, malnutrition, diabetes, chronic systemic diseases and infectious diseases occurring in hypovascularized bone may be associated with this condition $(7,22)$. In the present study, several fastidious strictly anaerobic bacteria commonly present in the dental biofilm were detected, suggesting that the source of infecting pathogens in osteomyelitis of the jaws is likely to be gingivitis, chronic periodontitis, previous dental extractions or endodontic treatments.

The presence of different oral anaerobic species in mixed infections suggests that ecological associations may be relevant in the development of osteomyelitis of the mandible and maxilla, since most oral anaerobes depend on favorable environmental conditions and complex ecological interactions with different microbial species to develop its capacity to attack and colonize other areas of the host $(7,24)$. Therefore, it is possible that pathogens different from those of the oral microbiota may reach the bone tissues through transient bacteremia, which are common after surgical procedures or traumas (26).

Mixed anaerobic infections are common in osteomyelitis, especially in skull infections, varying from $33 \%$ (4) to $93 \%$ (8) of the cases, with a higher prevalence of anaerobes (2.4-3.9 species per sample) than aerobes (0.4 species per sample) (6, $8)$. In the current study, strict anaerobes were predominant in all mixed infections (3.8 species per sample), while aerobes and facultative anaerobes were less frequent (1.5 species per sample).

The microorganisms detected by culture or PCR from osteolytic lesions or granulation tissues most likely represent the microbiota associated with the lesions and not simply external contaminants. Absence of the most common inhabitants of the oral cavity, including $S$. mutans, $S$. salivarius, S. sanguinis, and S. sobrinus, suggests that crosscontamination with oral tissues and dental biofilm was minimized during collection, since samples were obtained through surgical procedures.

Our data showed that the participation of Enterobacteriaceae and other enteric bacteria, such as Enterococcus faecalis, usually associated with immunosuppressed patients, nosocomial and multi-resistant infections $(7,23,28)$, is relevant in the microbiota detected in cases of chronic osteomyelitis of the jaws.

Actinomycetes are frequently isolated from oral infections. The results of culture and PCR confirm that A. israelii is the most common member of this genus in chronic osteomyelitis of the jaws. In the current study, all patients exhibited clinical history of periodontal diseases, dental extractions or endodontic treatment, which could facilitate the dissemination of Actinomyces to damaged tissues and the development of chronic infection (18). In this investigation, all samples with Actinomyces species were collected from the mandible, which presents poor vascular supply when compared with the maxilla, as previously reported (5).

Actinomyces is almost invariably isolated as part of polymicrobial microbiota, which commonly includes periodontal bacteria, Staphylococcus, Streptococcus, and Enterococcus spp. (24), as also evidenced in our study. In mixed microbiota, facultative or aerotolerant bacteria, such as actinomycetes and oral streptococci, may facilitate osteolysis, enabling the most active proteolytic Gram-negative anaerobes; for instance $P$. gingivalis and other black-pigmented Porphyromonas and Prevotella species, to survive in bone lesions or within environments with reduced redox potential inside osteolytic cavities $(5,18,19)$. These conditions often result in recurrent disease and inconsistent responses to antimicrobial agents, especially in chronic infections (7).

The prevalence of anaerobic gram-positive cocci, especially Parvimonas micra in osteomyelitis was also previously described $(4,7)$. These microorganisms are frequently isolated from periodontitis and gingivitis patients, as well as from dental periapical abscesses and other mixed anaerobic infections (17), however their virulence factors have not been fully elucidated (23). 
In this study, the presence of $F$. nucleatum in chronic osteomyelitis was associated with the presence of chronic suppuration and draining sinus tract. This phenomenon may be related to the ability of these anaerobes to stimulate host immune responses and inflammation. In addition, fusobacteria have been implicated in complex ecological interactions, creating conditions for the establishment of black-pigmented Porphyromonas and Prevotella, as well as anaerobic grampositive cocci, which are commonly associated with osteolytic lesions and other odontogenic infections $(7,17)$. These Gramnegative anaerobes, particularly $P$. gingivalis, may also induce tissue damage due to their ability to stimulate cytokine secretion, adhesion and host tissues invasion, and activation of osteoclasts.

This study suggests that cases of chronic osteomyelitis of the jaws are usually due to mixed anaerobic infections caused by oral microorganisms, especially those from the subgingival biofilm, frequently associated to staphylococci and enteric microorganisms.

\section{ACKNOWLEDGMENTS}

This study was supported by grants from Fundação de Amparo à Pesquisa do Estado de São Paulo (FAPESP, Proc. 02/07371-0 and 07/54851-0).

\section{REFERENCES}

1. Antony, B.; Thomas, S.; Chandrashekar, S.C.; Kumar, M.S.; Kumar, V. (2009). Osteomyelitis of the mandible due to Aggregatibacter (Actinobacillus) actinomycetemcomitans. Indian J. Pathol. Microbiol. 52 (1), 115-116.

2. Avila-Campos, M.J.; Velàsquez-Melèndez, G. (2002) Prevalence of putative periodontopathogens from periodontal patients and healthy subjects in São Paulo, SP, Brazil. Rev. Inst. Med. Trop. S. Paulo 44, 15.

3. Brady, B.A.; Leid, J.G.; Costerton, J.W.; Shirtliff, M.E. (2006) Osteomyelitis: clinical overview and mechanisms of infection persistence. Clin. Microbiol. Newsletter 28, 65-72.

4. Brook, I. (1986). Anaerobic osteomyelitis in children. Pediatr. Infect. Dis. 5, 550-556.

5. Brook, I. (2008). Actinomycosis: diagnosis and management. Southern Med. J. 101,1019-1023.
6. Brook, I. (2008). Microbiology and management of joint and bone infections due to anaerobic bacteria. J. Orthop. Sci. 13, 160-169.

7. Brook, I.; Frazier, E.H. (1993). Anaerobic osteomyelitis and arthritis in a military hospital: a 10-year experience. Am. J. Med. 94, 2-8.

8. Calhoun, K.H.; Shapiro, R.D.; Stiernberg, C.M.; Calhoun, J.H.; Mader, J.T. (1988). Osteomyelitis of the mandible. Arch. Otolaryngol. Head Neck Surg. 114, 1157-1162.

9. Cheng, S.; McCleskey, F.K.; Gress, M.J.; Petroziello, J.M.; Liu, R.; Namdari, H.; Beninga, K.; Salmen, A.; Del Vecchio, V.G. (1997). A PCR assay for identification of Enterococcus faecium. J. Clin. Microbiol. $35,1248-1250$.

10. Coviello, V.; Stevens, M.R. (2007). Contemporary concepts in the treatment of chronic osteomyelitis. Oral Maxillof. Surg. Clin. N. Am. 19, 523-534.

11. Fenollar, F.; Roux, V.; Stein, A.; Drancourt, M.; Raoult, D. (2006) Analysis of 525 samples to determine the usefulness of PCR amplification and sequencing of the 16S rRNA gene for diagnosis of bone and joint infections. J. Clin. Microbiol. 44, 1018-28.

12. Foschi, F.; Cavrini, F.; Montebugnoli, L.; Stashenko, P.; Sambri, V.; Prati, C. (2005). Detection of bacteria in endodontic samples by polymerase chain reaction assays and association with defined clinical signs in Italian patients. Oral. Microbiol. Immunol. 20, 289-295.

13. Fouad, A.F.; Barry, J.; Caimano, M.; Clawson, M.; Zhu, Q.; Carver, R.; Hazlett, K.; Radolf, J.D. (2002). PCR-based identification of bacteria associated with endodontic infections. J. Clin. Microbiol. 40, 3223-3231.

14. Harada, K.; Tsuneyama, K.; Sudo, Y.; Masuda, S.; Nakanuma, Y. (2001). Molecular identification of bacterial 16S ribosomal RNA gene in liver tissue of primary biliary cirrhosis: is Propionibacterium acnes involved in granuloma formation? Hepatology 33, 530-536.

15. Hoshino, T.; Kawaguchi, M.; Shimizu, N.; Hoshino, N.; Ooshima, T.; Fujiwara, T. (2004). PCR detection and identification of oral streptococci in saliva samples using gtf genes. Diag. Microbiol. Infect. Dis. 48, 195199.

16. Kim, S.G.; Jang, H.S. (2001). Treatment of chronic osteomyelitis in Korea. Oral Surg. Oral Med. Oral Pathol. Oral Radiol. Endod. 92, 394398.

17. Kuriyama, T.; Karasawa, T.; Nakagawa, K.; Yamamoto, E.; Nakamura, S. (2002). Bacteriology and antimicrobial susceptibility of gram-positive cocci isolated from pus specimens of orofacial odontogenic infections. Oral Microbiol. Immunol. 17, 132-135.

18. Long, J.B.; Collins, J.M.; Beauchamp, C.P.; Kho, R.; Cornella, J.L. (2007). Actinomyces meyeri osteomyelitis of the symphysis pubis following pubovaginal sling. Int. Urogynecol. J. 18, 1375-1378.

19. Lugassy, G.; Shaham, R.; Nemets, A.; Ben-Dor, D.; Nahlieli, O. (2004). Severe osteomyelitis of the jaw in long-term survivors of multiple myeloma: a new clinical entity. Am. J. Med. 117, 440-441.

20. Martineau, F.; Picard, F.J.; Ke, D.; Paradis, S.; Roy, P.H.; Ouellette, M.; Bergeron., M.G. (2001). Development of a PCR assay for identification of staphylococci at genus and species levels. J. Clin. Microbiol. 39, 2541- 
2547.

21. Möller, A.J. (1966). Microbial examination of root canals and periapical tissues of human teeth: methodological studies. Odontol. Tidskr. 74:1138.

22. Prasad, K.C.; Prasad, S.C.; Mouli, N.; Agarwal, S. (2007). Osteomyelitis in the head and neck. Acta Oto-Laryngol 127, 194-205.

23. Scolozzi, P.; Lombardi, T.; Edney, T.; Jaques, B. (2005). Enteric bacteria in mandibular osteomyelitis. Oral Surg. Oral Med. Oral Pathol. Oral Radiol. Endod. 99, 42-46.

24. Sharkawy, A.A. (2007). Cervicofacial actinomycosis and mandibular osteomyelitis. Infect. Dis. Clin. N. Am. 21, 543-556.

25. Spilker, T.; Coenye, T.; Vandamme, P.; Lipuma, J.J. (2004). PCR-based assay for differentiation of Pseudomonas aeruginosa from other Pseudomonas species recovered from cystic fibrosis patients. J. Clin. Microbiol. 42, 2074-2079.

26. Takai, S.; Kuriyama, T.; Yanagisawa, M.; Nakagawa, K.; Karasawa, T. (2005). Incidence and bacteriology of bacteremia associated with various oral and maxillofacial surgical procedures. Oral Surg. Oral Med. Oral Pathol. Oral Radiol. Endod. 99, 292-298.

27. Xia, T.; Baumgartner, J.C. (2003). Occurrence of Actinomyces in infections of endodontic origin. J. Endod. 29, 549-552.

28. Zuluaga, A.F.; Galvis, W.; Saldarriaga, J.G.; Agudelo, M.; Salazar, B.E.; Vesga, O. (2006). Etiologic diagnosis of chronic osteomyelitis. Arch Intern Med. 166, 95-100. 